\title{
A MOLECULAR-BASED APPROACH TO INVESTIGATE BREAST CANCER 1 AND BREAST CANCER 2 STATUS IN OVARIAN CANCER AMONG IRAQI WOMEN
}

\author{
MUHANNAD SHWEASH ${ }^{1 *}$, SADDAM JUMAA NASEER ${ }^{2}$, MAISAM KHIDER AL-ANII ${ }^{3}$,THULFIQAR FAWWAZ MUTAR ${ }^{4}$
}

${ }^{1}$ Department of Clinical Laboratories Sciences, College of Pharmacy, University of Anbar, Anbar, Ramadi, Iraq. ${ }^{2}$ Department of

Pharmaceutics, College of Pharmacy, University of Anbar, Anbar, Ramadi, Iraq. ${ }^{3}$ Department of Basic Sciences, College of Dentistry, University of Anbar, Anbar, Ramadi, Iraq. ${ }^{4}$ Department of Environmental Studies, Institute of Graduate Studies and Research, Alexandria University, Alexandria, Egypt. Email: Dr.muhannadshweash@gmail.com

Received: 09 February 2018, Revised and Accepted: 03 April 2018

\section{ABSTRACT}

Objective: Cancer ovary is one of the fatal gynecologic malignancies worldwide. Since breast cancer (BRCA) genes are considered tumor suppressor genes and play important roles in cancer by repairing of chromosomal damage with the error repair of DNA breaks. Therefore, breast cancer 1 (BRCA1) and breast cancer 2 (BRCA2) gene mutations strongly enhance the development of ovarian cancer risk among women. Here, we report that both genes are an essential mediator of progress ovarian cancer, to determine the influence of BRCA1 and BRCA2 mutations in the improvement of ovarian cancer.

Methods: A total of 25 subjects were chosen for the genetic studies, and three groups were recruited: fifteen ovarian cancer patients group, five healthy controls, and five first-degree relatives to a known case of ovarian cancer patients.

Results: A genetic analysis revealed that a strong correlation exists between both gene mutations' status in ovarian cancer, and BRCA gene mutations (185delAG, 5382insC, and 4153delA in BRCA1 and 6174delT in BRCA2) remained to establish to have a relatively high frequency among people in this study among ovarian cancer patients. Furthermore, seven patients with ovarian cancer carried all of the four investigated mutations, and five had three mutations.

Conclusion: Otherwise, BRCA gene frequency showed low prevalence among first-degree relatives, and to a lesser extent among healthy controls, with only a few had all of the mutations combined. These data demonstrate for the first time a molecular link between BRCA1 and BRCA2 mutations in ovarian cancer progression in Iraq.

Keywords: Breast cancer 1, Breast cancer 2, Mutation, Ovarian cancer, Polymerase chain reaction.

(c) 2018 The Authors. Published by Innovare Academic Sciences Pvt Ltd. This is an open access article under the CC BY license (http://creativecommons. org/licenses/by/4. 0/) DOI: http://dx.doi.org/10.22159/ajpcr.2018.v11i7.25217

\section{INTRODUCTION}

Cancer is one of the most important health problems of malignant diseases. This disease arises due to the abnormal division of cells without cellular control. The condition that accompanies surrounding healthy tissue is due to tumor formation and abnormal growth of this tumor. This will result in an invasion of the neighboring tissues and metastasis in other organs through blood or lymphatic stream [1]. Ovarian cancer affects many women in the world. Therefore, the cancer of ovary has developed the greatest common malignancy and the subsequent main cause of cancer death in western women. The development and progression of ovarian cancer are controlled by complex mechanisms that are still not completely understood. Several aspects of this disease such as grade, genetics, and oncogene suppressor gene expression seem to be more heterogeneous, its related features involving tumor molecular events and hormonal and biological characteristics are particularly difficult. Ovarian cancer is a challenging health problem; there are two factors concerning its etiology and these are genetic and environmental issues. However, the pathogenesis of this cancer related with many hormonal and lifestyle aspects which demonstrated has an essential role in this cancer, and these aspects include one of the largest risk factors of family history of such disease [2]. The first degree in a woman with a relative affected with ovarian cancer is correlated with improved risk of ovarian cancer in a three-fold ratio [3].

So far, there are several high-risk ovarian cancer susceptibility variants, two different genes named BRCA1 and BRCA2, both genes recognized to be best factors in the molecular events in the virulence of ovarian cancer.
BRCA1 and BRCA2 have an important function as tumor suppressor genes and encode proteins involved in deoxyribonucleic acid (DNA) repair [2]. Several lines of evidence strongly suggest that the women carrying mutations in these 2 genes have an affectedly increased risk of developing ovarian cancer in their lifetime. Interestingly, more than 400 different mutations have been identified in these two genes, BRCA1 and a nuclear polypeptide of $220 \mathrm{kDa}$ (1863 amino acids) encodes, and located on chromosome 17q12-21, In families with a high percentage of breast cancer (BRCA) either in early-onset BRCA or ovarian cancer happens, the majority of ovarian cancer incidence followed by the mutation of gene 1 .

Furthermore, in high risk families the second gene which encodes a $384 \mathrm{kDa}$ (3418 amino acids) and located on chromosome 13q12.1 is similarly considered as an increased risk factor of ovarian and BRCA mutation [4]. Numerous reports demonstrated that the majority of breast and ovarian cancers within these high-risk families appeared to involve by these two genes, and molecular investigations for the percentage of breast and ovarian cancer within the people that might be to address such ovarian susceptibility genes still undocumented. The observation demonstrated that BRCA1 protein has a significant role in the signaling of DNA damage and in DNA repair, although the mechanism of action has not yet been adequately addressed. For this reason, several genetic studies have suggested that intracellular mechanism pathway involving a response to DNA damage, transcription, and interaction with other proteins included in DNA repair and apoptosis was contributed to the major roles of both genes [5]. BRCA1 and BRCA2 mutations have 
been investigated in numerous studies using breast and ovarian cancer. However, to the best of our knowledge, only two studies have reported a comparison percentage of the disease related to the expression profiles of mutation, BRCA1 mutation in women assessed to have risk factor between $26 \%$ and $54 \%$ for developing ovarian cancer, while in BRCA2 mutation assessed the percentage between $10 \%$ and $23 \%[6,7]$.

El-Harith et al. [8] had further examined the prevalence of both genes mutation for tumorigenesis in ovarian and BRCA and assessment of the benefits and limitations of molecular testing for these cancers. Essentially, some authors have described that testing of molecular events for susceptibility to cancer appears mainly suitable for the family to have been documented at high-risk cancer. Expressing of such abnormal mutations related to the subgroup of this family, mutation of these genes is considered as a possible diagnostic tool with clinical findings. The early truncate of proteins induced non-sense mutation which is considered common pathological mutations [5]. Since the lack of general population documents and multiplicity of BRCA1 and BRCA2 mutations developed problematic to control the specific risk estimate for each mutation which may enhance these mutations that are significant raise the risk for breast and ovarian cancer. One study described two specific population mutations with BRCA1 185delAG and 5382 insC while 6174 delT mutation with BRCA2 among Ashkenazi women in percent of $60 \%$ in ovarian and $30 \%$ in primary BRCA respectively [9].

The aim of the current study was to classify BRCA1 and BRCA2 mutation in Iraqi women with ovarian cancer and considered as molecular tools detection. Here, we show that in ovarian cancer gene mutations, ranks are upregulated and the mechanism by which maintenance of these mutations is succeeded to improve progression in ovarian cancer. Finally, fast development is one guarantee of ovarian tumor and these data demonstrated that this gene may promise for specific gene therapy for this type of cancer.

\section{METHODS}

\section{Patient samples}

This is a reconsidering study of patients diagnosed and treated for ovarian malignancy during their life. Clinical samples (blood) were collected from three groups of women; and two of these groups are undergoing radical ovariectomy for the treatment of ovarian cancer. A total of 25 samples were selected for the genetic studies, and the primary set of samples were obtained from women (age 45-70 years) attending the clinic of detection of ovarian cancer who were admitted to Al-Ramadi Teaching Hospital in Ramadi city (Iraq). Again, three groups were recruited: Fifteen ovarian cancer patients group, five healthy as controls, and five first-degree relatives to a documented case of ovarian cancer patients. Patient's history was obtained from patient giving blood samples. Patient approval to participate in scientific research was taken according to the approval certificate from Maternity and Child Teaching Hospital.

\section{Polymerase chain reaction (PCR)}

\section{Total DNA extraction from blood samples}

In brief, genomic DNA was obtained from blood samples by Quick Prep Total DNA Purification Kit (Geneaid, UK) according to the producer guidelines. The DNA isolated from the samples was separately labeled and kept for the following procedure.

\section{PCR primers}

The oligonucleotide primers were synthesized by SIGMA ${ }^{\circledR}$. On arrival, they were suspended to the appropriate stock concentration with ultrapure water and stored at $-20^{\circ} \mathrm{C}$. For PCR applications, the primers were diluted to $10 \mathrm{pmol} / \mu \mathrm{l}$ as a working concentration.

\section{PCR of ovarian cancer markers}

Here, we describe a simple and rapid method for the simultaneous detection of four common mutations: The primers were designed to amplify a $275 \mathrm{bp}$ fragment of $185 \mathrm{delAG}, 425 \mathrm{bp}$ of 5382insC, and $134 \mathrm{bp}$ of $4153 \mathrm{delA}$ in BRCA1 and $534 \mathrm{bp}$ of 6174 delT in BRCA2. For more description, to amplify genes encoding ovarian cancer with PCR technique, the primers and PCR conditions are indicated in Fig. 1. The sample of PCR reaction in the volume of $25 \mu \mathrm{l}$ contains the following materials, $2.5 \mu \mathrm{l}$ of each upstream and downstream primer, $2.5 \mu \mathrm{l}$ of free nuclease water, $5 \mu \mathrm{l}$ of DNA extraction, and $12.5 \mu \mathrm{l}$ of master mix.

\section{DNA agarose gel electrophoresis}

The PCR products were electrophoresed for sizing and qualitative analysis using a horizontal submarine mini-gel apparatus, 1\% agarose gels (Bioscience Services, UK), and electrophoresis power supply (Kodak UK). $15 \mu \mathrm{l}$ of the PCR reaction was added to $2 \mathrm{ul}$ of Gel Loading Buffer (Bioline, UK) and electrophoresed for $1 \mathrm{~h}$ at $60 \mathrm{~V}$ in a $\times 1$ TAE $(89 \mathrm{mM}$ Tris-base, $2 \mathrm{mM}$ Na2-EDTA, $89 \mathrm{mM}$ Boric Acid, $\mathrm{pH}$ 8.3) buffered $2 \% \mathrm{w} / \mathrm{v}$ agarose gel (Bioline, UK) with $\times 1$ TAE which is buffer for running. $2 \mu \mathrm{l}$ of a $10 \mathrm{mg} / \mathrm{ml}$ solution was added of ethidium bromide (Sigma, UK) to the agarose before pouring to permit visualization of the DNA fragments electrophoresed on a $312 \mathrm{~nm}$ UV trans illuminator (Syngene, UK). The size marker used was appropriate to the size of the amplicon and in this instance was an allelic ladder (Promega, USA).

\section{RESULTS}

In ovarian cancer, the expression of genes are varies, these genes contain several well-known ovarian cancer-associated gene transmutations, involving "185delAG, 5382insC and 4153delA (BRCA1) and 6174delT (BRCA2)." PCR technique analysis showed a single band for all the mutations studied at the corresponding molecular weight in each gene. Therefore, to identify these mutations above in human ovarian cancer, we evaluated in this study major markers which have been screened for the main mutations overhead and are illustrated in (Figs. 2-5) respectively.

In the present study, the results were shown that the overall frequency of BRCA genes mutation was more often detected among ovarian cancer patients than others included in the study. Seven patients with ovarian cancer carried all of the four analyzed mutations, while five of them had three mutations. Otherwise, BRCA gene frequency showed low prevalence among first-degree relatives and to a lesser extent among healthy controls, with only a few had all of the mutations combined.

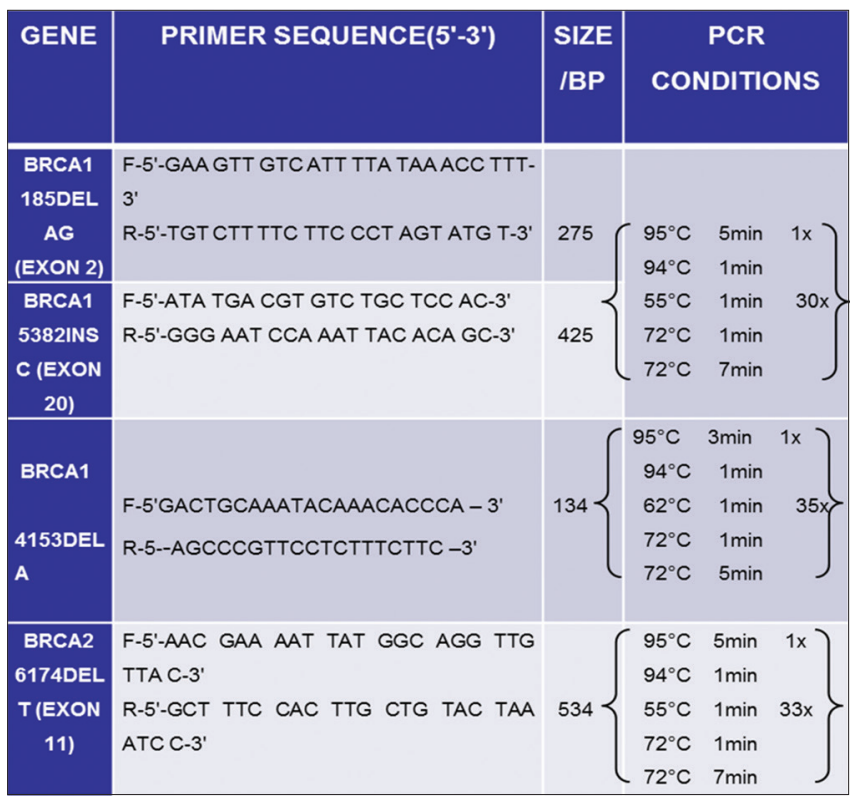

Fig. 1: Overview of primers sequences and polymerase chain reaction condition to detect breast cancer 1 and breast cancer 2 genes expression 


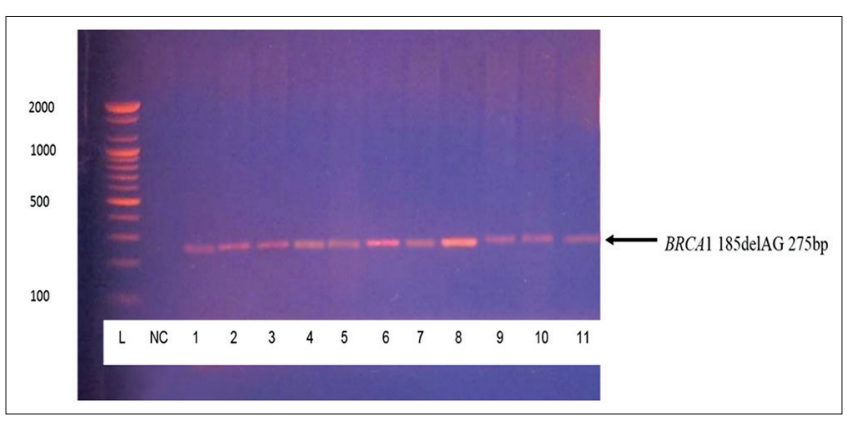

Fig. 2: The expression of breast cancer 1 (BRCA1) 185delAG amplicon product in ovarian cancer. Samples were prepared, separated by gel electrophoresis of polymerase chain reaction as outlined in materials and methods, and then assessed for the BRCA1 185delAG amplicon product. L: ladder; NC: negative control; 1, 2, 3, 4, 5, 6, 7, 8: number of an ovarian cancer patient; 9, 10: number of the first-degree relatives; 11: healthy control.

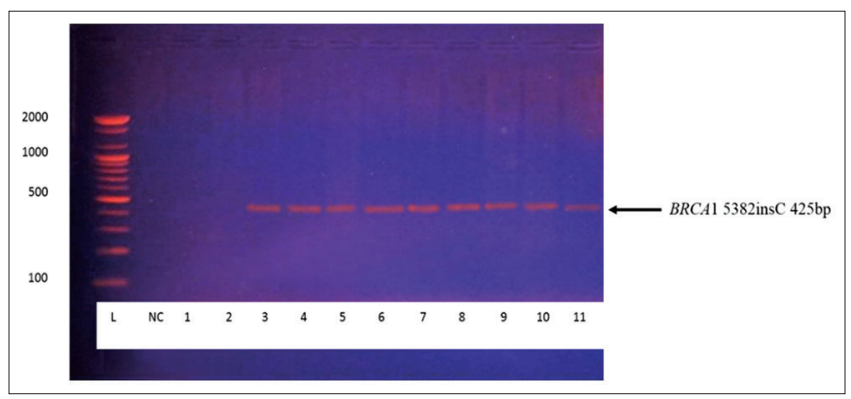

Fig. 3: The expression of breast cancer 1 (BRCA1) 5382insC amplicon product in ovarian cancer. Samples were prepared, separated by gel electrophoresis of polymerase chain reaction as outlined in materials and methods, and then assessed for BRCA1 5382insC amplicon product. L: ladder; NC: negative control; 1, 2, 3, 4, 5, 6, 7, 8: number of an ovarian cancer patient; 9, 10: number of the first-degree relatives; 11: healthy control.

The frequency of BRCA1 (185delAG) was the most frequently recorded mutation, it was detected in $66 \%(10 / 15)$ of patients of ovarian cancer, while only $20 \%(1 / 5)$ healthy control subjects carried this mutation. On the other side, both the first-degree relatives had the frequency of this type of BRCA mutation giving a value of $40 \%(2 / 5)$. Interestingly, the significant increase of mutation related with the patient no 8 presented that the assessed generation risk of ovarian cancer progress was higher in 2 times due to overexpressed of this c.6869delAG (185delAG) mutations (66\%) than of the mutation of c.5266dupC (29\%). Increased gene activity as determined with 185delAG that recognizes BRCA1 at its activation loop correlated with enhanced expression of the mutation (Fig. 2). Conversely, the mutation of 185 delAG documented arises between people with ovarian cancer among the different population.

Since the previous figure in this study indicates 185delAG stability and activity in all samples, we next examined the BRCA1 (5382insC). Therefore, the observation as shown in Fig. 3 on BRCA1 (5382insC) mutation was found in 7/15 patients of ovarian cancer, forming $46 \%$ of this group. In contrast, the healthy controls had the lowest frequency of this gene mutation, with $20 \%$ carriage rate (1/5). Likewise, $40 \%(2 / 5)$ of the first-degree relative had the mutation. Surprisingly, not similar to other mutations mentioned above in our results, BRCA1 (4153delA) mutation was low (Fig. 3).

Regarding to the 4153delA gene, of fifteen samples tested of ovarian cancer, only one patient was positive for 4153delA gene expression at a usual molecular weight of $134 \mathrm{pb}$, forming $6.6 \%$ of this group (mean \pm standard error of mean (SEM) 83.4 \pm 5.47 ). Whereas the other patients lack this mutation (Fig. 4). Probably, these subsets of patient samples explicit the greater molecular weight irregular of mutations, we identified other mutations related to this study for ovarian cancer samples. The irregular spreading of 4153delA allele carriers may reveal a comparatively recent origin of this genetic variant. In future work, these need more investigation in people with ovarian cancer.

Next, we assessed the BRCA2 gene mutation (6174delT). The results showed that five ovarian cancer patient samples $(33 \%)$ were carrier of mutation in the exon 11 of BRCA2 gene (mean \pm SEM $81.14 \pm 2.56$, $60.08 \pm 3.82,60.32 \pm 2.52,53.00 \pm 4.36$ and $85.85 \pm 5.09$ ), and only one out of five (20\%) of first-degree relatives have been showed appeared of this mutation (mean \pm SEM $51.97 \pm 4.24$ ). In this population, BRCA1 mutations were common (185delAG and 5382insC) (Fig. 5).

Nevertheless, when compared to the incidence of both genes' mutation between targeted carriers, the incidence of BRCA2 mutations is different about $50 \%$ that of BRCA1 mutations, giving a finding of carriers with BRCA2 persist unaffected. In this study, we established that, in which people were determined frequently depending on the sufficient family history, the BRCA2-6174delT mutation was approximately half as frequent as the BRCA1-185delAG and 5382insC mutations combined.

At this point, the purpose for the dominance of BRCA1 mutations among this population unclear, molecular explanation of this matter may be due to restricted to this gene in the founder effects. Even though the ovarian cancers related to inherited mutations in cancer susceptibility genes represent a small proportion of all cancers, it is of great importance for the clinician to detect the patients who are carrying these mutations. Consequently, the determination of potential risk among the family members of the mutation carrier can be estimated and prevention measures can be undertaken. Focusing on this target gene to reduce the ovarian cancer risk could develop a novel approach for early molecular diagnostic tools in ovarian malignancy.

The carriers of BRCA1 and BRCA2 gene mutations increase the risk factor and developing ovarian cancers during their lifetime. Particularly, the BRCA1 defect influences to early beginning of the hereditary ovarian cancer because both genetic and environmental converters are possible to influence low-penetrance mutations than high-penetrance mutations. These findings are dependable with earlier observations of lower penetrance of BRCA2 and more related to the BRCA2-6174delT mutation. As illustrated above, studies in a high-risk people found ovarian cancer risk which is higher in BRCA1 compared with BRCA2 families.

To our information, the different expression among BRCA1 and BRCA2 still needs more investigation in this present study. Consequently, women with BRCA1 mutations showed a high level of risk factor and developing the disease (40\%) comparing with a low level of BRCA2 mutations group (20\%). The diseases which develop the relation to ovarian cancers in both above gene mutations are commonly serous papillary carcinomas, though endometrial and clear cell carcinomas may be happening. In summary, this study provides evidence that BRCA1 plays a key role in ovarian cancer patients. It is important to highlight that there has been a significant interest in the development of these gene mutations as genetic therapy. During this study, samples investigated were limited number $(25$ samples for three groups), although these restrictions, our findings may be valued for additional studies on other genes related to this type of malignant organ.

\section{DISCUSSION}

In support of this discussion, a previous study by Fodor et al. revealed that almost of heritable ovarian carcinomas proposed due to the high prevalence of BRCA1 mutation comparing in small prevalence in the involvement of BRCA2 mutations [10]. Therefore, we found a significant difference in prevalence between BRCA1 and 2 which was a high percentage with BRCA1 mutations than in those with BRCA2 mutations among ovarian cancer women. In addition, there are some factors which play a critical role in enhancement the activate risk of 


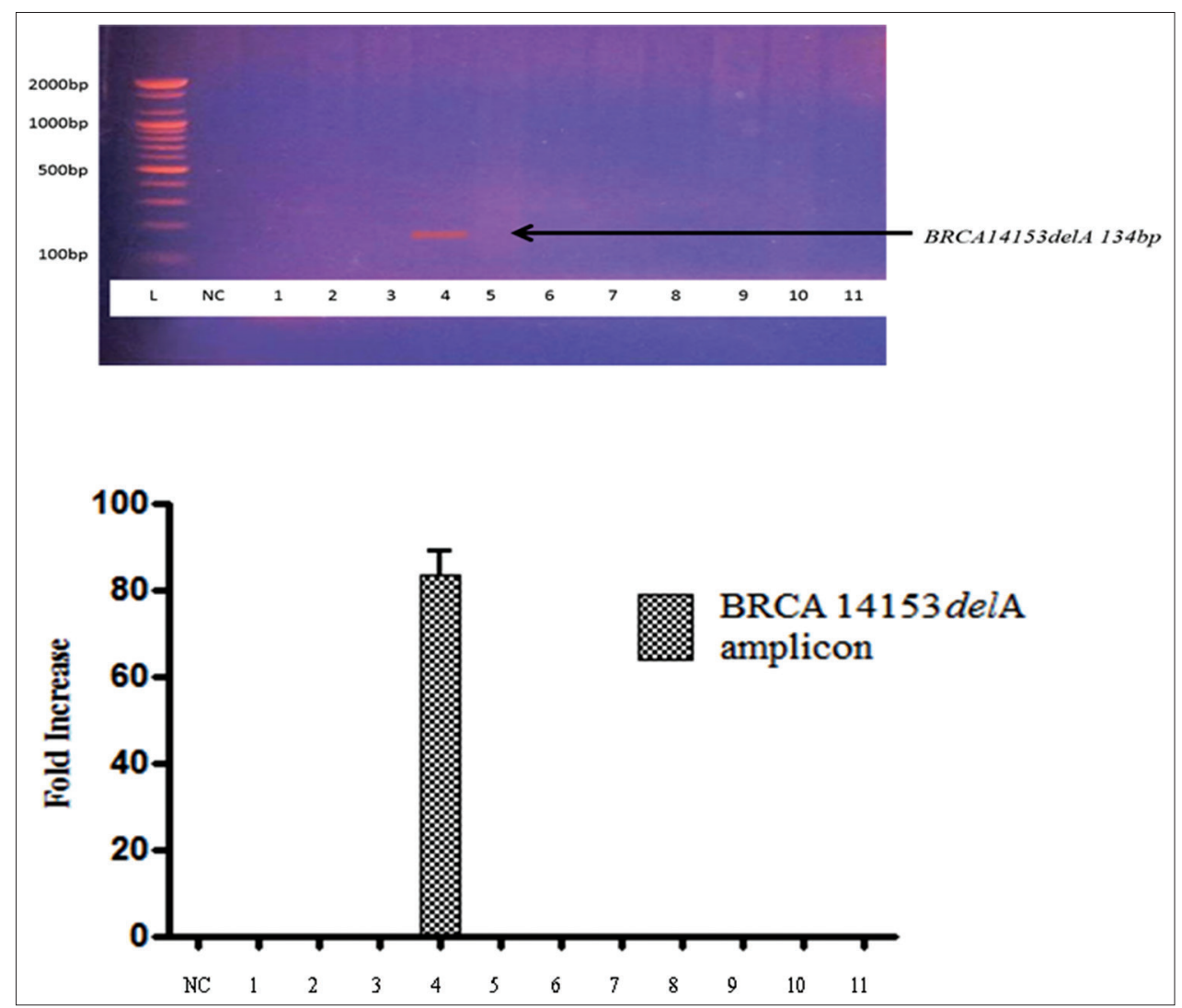

Fig. 4: The expression of breast cancer 1 (BRCA1) 4153delA amplicon product in ovarian cancer. Samples were prepared, separated by gel electrophoresis of polymerase chain reaction as outlined in methods, and then assessed for (a) BRCA14153delA amplicon product. Gels were quantified for (b) fold expression by scanning densitometry (mean \pm standard error of mean 83.46 \pm 5.47 ); L: Ladder; NC: 15 Negative control; 1, 2, 3, 4, 5, 6, 7, 8: Number of ovarian cancer patient; 9, 10: Number of the first-degree relatives; 11: healthy control

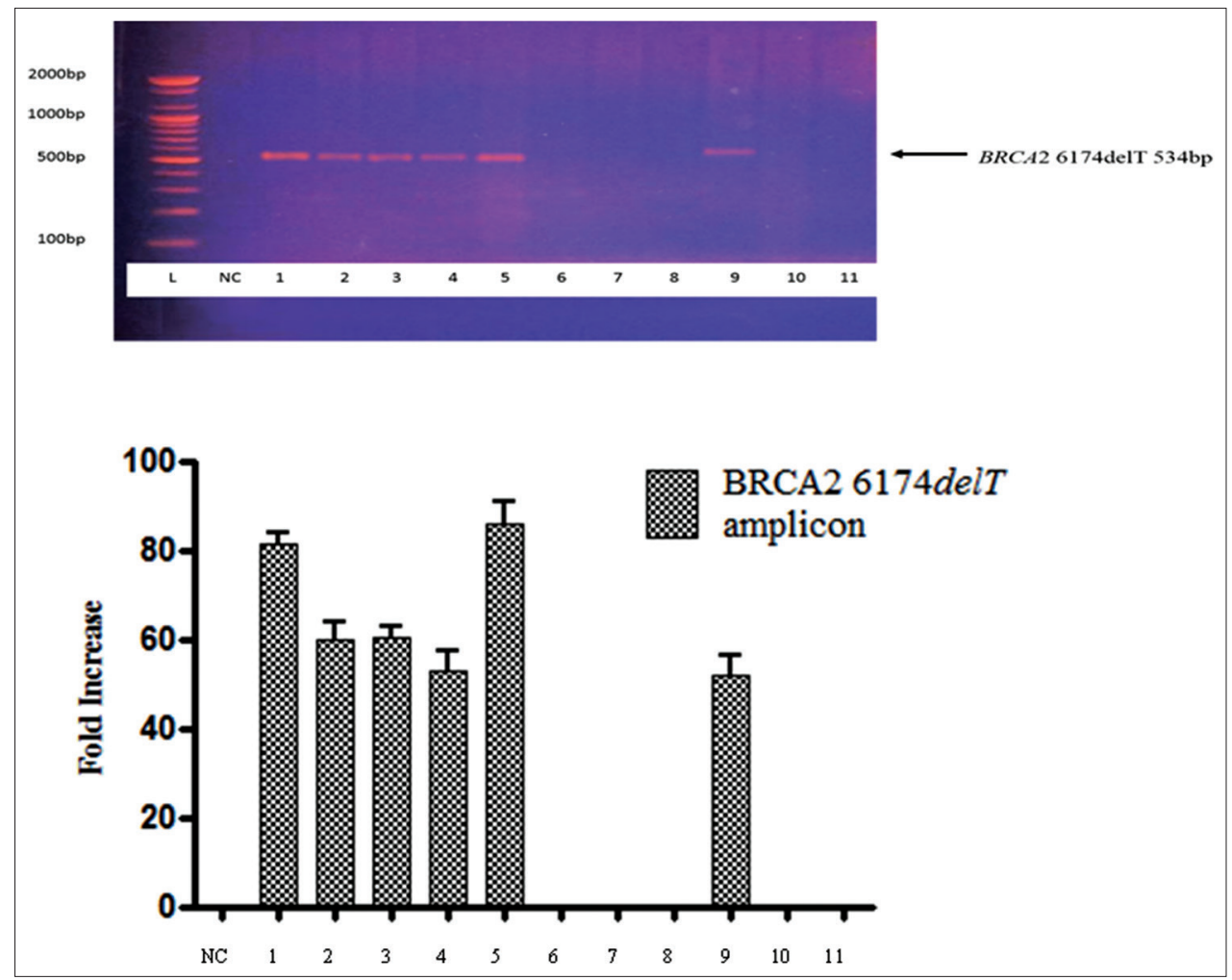

Fig. 5: The expression of breast cancer 2 (BRCA2) 6174delT amplicon product in ovarian cancerSamples were prepared, separated by gel electrophoresis of polymerase chain reaction as outlined in methods, and then assessed for (a) BRCA2 6174delT amplicon product. Gels were quantified for (b) fold expression by scanning densitometry (mean \pm standard error of the mean); L: Ladder; NC: Negative control; 1 , $2,3,4,5,6,7,8$ : Number of ovarian cancer patient; 9, 10: Number of the first-degree relatives; 11: Healthy control 
increasing ovarian cancer, such as parity, contraceptive oral drug, and oophorectomy. High levels of androgen in women indicated highly predisposed to a tumor of ovarian [11]. The recent study by Iyer $e t a l$. demonstrated that different population is established with a specific transcript of BRCA1 of the chromosome 17. These variations of nucleotide indicated risk issues in genetic ovarian and BRCA syndrome in the worldwide population [12]. In addition, another mutation in cytochrome b gene related to the mitochondrial genome indicated as expected to be possibly pathogenic in the event of ovarian cancer patients [13]

According to the ethnic groups, the evidence of 185delAG mutation was significantly different depending on the different population. The previous study demonstrated that the percentage of this mutation was the actual high frequency of $31.6 \%$ among non-Jewish Americans of Spanish ancestry from the San Luis Valley, Colorado [14]. In contrast to other studies, this mutation was variable low frequency (1.13-5.9\%) in a group of Americans Americans, the Spanish from Spain, Polish, Iranian, Pakistani, and Turkish women $[15,16]$. The evidence of BRCA1 185delAG mutation in "Jewish" was described for the non-Ashkenazi population through the Middle East, Greece, Turkey, and England (Yorkshire) in addition in two Indo-Pakistani families [17]. Taken together, this indicated that the mutation happens in a recurrence segment of BRCA1; with non- Ashkenazi ethnic groups may explain how the different haplotypes depending on a high mutation rate in this repeat region [18]. Likewise, $40 \%(2 / 5)$ of the first- degree relative had the mutation. In addition, among Ashkenazi Jews, this mutation was common, and it was established in approximately $25 \%$ of mutation in high hereditary risk of ovarian and BRCAs among Jewish women [19]. A previous study by Csokay et al. [20] has been demonstrated that the finding from limited cases proposed that the mutation of 5382insC also evident in women suffering breast and ovarian cancer from Hungary and Latvia.

Our results are agreement with another result, similar as previously determined by Gayther et al. [21], who also observed that the mutation of BRCA1 4153delA was the remarkable rate in percent of $2 / 177(1.1 \%)$ in Russian cancer families related to ovarian cancer. Respectively, this mutation also indicated in Lithuania, Latvia, Belarus, and Poland [22,23]. Notably, other findings demonstrated that the prevalence of this mutation was more association in ovarian than breast type. On the another hand, several other reports have established an improved incidence of ovarian cancer patients with the mutation of 4153delA carriers $[24,25]$. While, other study indicated that the most common mutation among population level was BRCA2-6174delT in valued carrier incidence of $1.4 \%$, compared with $1.1 \%$ with combined of BRCA1 mutations [26]. The correlation percentage between BRCA1 and BRCA2 from above studies was not observed at the same percentage in our study; however, the carriers of 6174delT mutation considered greater risk of ovarian cancer than the percent of BRCA2 risks $(20 \%$ vs. $11 \%)$, these data in agreement with previous findings demonstrated that mutations in the ovarian cancer are related with high risk for this type of cancer [27]. The proportion of the high-risk ovarian cancer attributable to BRCA1 and BRCA2 has been shown to vary considerably between different studies. A study by Antoniou et al. [6] was shown that 75 carriers were BRCA1 185delAG, while 69 were BRCA1 5382insC carriers, and 52 carriers were BRCA2 6174delT. In contrast, the chances of ovarian cancer for BRCA1 and BRCA2 mutation carriers are $16-63 \%$ and $10-27 \%$, respectively [7].

Since the syndromes of familial ovarian cancer linked to the gene mutations that happen on this gene, the people of ovarian cancers are affected by mutations on the BRCA1 or BRCA2 gene in approximately $10 \%$ [28]. Our findings in the present study advised that to consider the assessment of the common BRCA1 gene as a first target for screening in a high-risk population. Mutations with BRCA2 also confer a low risk of ovarian cancer. Interestingly, a family history of ovarian cancer is strongly predictive of a BRCA1 mutation and thus suggested that both genes remain highly candidate mutations in these genes substantially enhanced the developing risk of rising ovarian cancer.

\section{CONCLUSION}

The finding in this study has wide applications to deal with other types of tumor beyond ovarian cancer. Therefore, data in this study confirmed the identification of BRCA1 and BRCA2 among human ovarian cancer patients, which considered possible novel investigative or therapeutic targets in human ovarian cancer. Furthermore, these gene mutation expression sketches allow beneficial in convoluted gene appearance evaluates investing expression sketches from many various causes.

\section{ACKNOWLEDGMENTS}

The authors are grateful to all staff in the Maternity and Child Teaching Hospital and Al-Ramadi Teaching Hospital in Ramadi city, Iraq, and technical assistance staff.

\section{CONFLICTS OF INTEREST}

The authors that there were no conflicts of interest.

\section{REFERENCES}

1. Estanqueiro M, Amaral MH, Conceição J, Lobo JM. Evolution of liposomal carriers intended to anticancer drug delivery: An overview. Int J Curr Pharm Res 2015;6:3-10.

2. Chen Y, Lee WH, Chew HK. Emerging roles of BRCA1 in transcriptional regulation and DNA repair. J Cell Physiol 1999;181:385-92.

3. Wooster R, Neuhausen SL, Mangion J, Quirk Y, Ford D, Collins N. Localization of a breast cancer susceptibility gene, BRCA2, to chromosome 13q12- 13. Science 1994;265:2088-90.

4. King MC. Late-Breaking Research Session. Canada: American Society of Human Genetics Annual Meeting. Montreal Quebec; 1994.

5. Somasundaram K. Breast cancer gene 1 (BRCA1): Role in cell cycle regulation and DNA repair-perhaps through transcription. J Cell Biochem 2003;88:1084-91

6. Antoniou A, Pharoah PD, Narod S, Risch HA, Eyfjord JE, Hopper $\mathrm{JL}$, et al. Average risks of breast and ovarian cancer associated with BRCA1 or BRCA2 mutations detected in case series unselected for family history: A combined analysis of 22 studies. Am J Hum Genet 2003;72:1117-30.

7. King MC, Marks JH, Mandell JB. Breast and ovarian cancer risks due to inherited mutations in BRCA1 and BRCA2. Science 2003;302:643-6.

8. El-Harith EA, Abdel-Hadi MS, Doerk T, Badr AN, Schmidtke J. The potential benefits of genetic testing in breast and ovarian cancer. Saudi Med J 1999;20:663-70.

9. Satagopan JM, Boyd J, Kauff ND, Robson M, Scheuer L, Narod S, et al. Ovarian cancer risk in ashkenazi jewish carriers of BRCA1 and BRCA2 mutations. Clin Cancer Res 2002;8:3776-81.

10. Fodor FH, Weston A, Bleiweiss IJ, McCurdy LD, Walsh MM, Tartter PI, et al. Frequency and carrier risk associated with common BRCA1 and BRCA2 mutations in Ashkenazi Jewish breast cancer patients. Am J Hum Gen 1998;63:45-51.

11. Modugno F. Ovarian cancer and polymorphisms in the androgen and progesterone receptor genes: A HuGE review. Am J Epidemiol 2004;159:319-35.

12. Iyer P, Kumar S, Karthikeyan S, Namboori PK. 'BRCA1' responsiveness towards breast cancer-a population-wise pharmacogenomic analysis. Int J Pharm Pharm Sci 2016;8:267-70.

13. Taneja N, Kukal S, Mani S. Cytb: A hot spot for pathogenic mutations in mitochondrial genome of breast cancer and ovarian cancer patients. Int J Pharm Pharm Sci 2015;7:128-35.

14. Mullineaux LG, Castellano TM, Shaw J, Axell L, Wood ME, Diab S, et al. Identification of germline $185 \mathrm{delAG}$ BRCA1 mutations in nonJewish Americans of Spanish ancestry from the San Luis Valley, Colorado. Cancer 2003;98:597-602.

15. Rashid MU, Zaidi A, Torres D, Sultan F, Benner A, Naqvi B, et al. Prevalence of BRCA1 and BRCA2 mutations in Pakistani breast and ovarian cancer patients. Int J Cancer 2006;119:2832-9.

16. Weitzel JN, Lagos V, Blazer KR, Nelson R, Ricker C, Herzog J, et al. Prevalence of BRCA mutations and founder effect in high-risk Hispanic families. Cancer Epidemiol Prev Biomarkers 2005; 14:1666-71.

17. Risch HA, McLaughlin JR, Cole DE, Rosen B, Bradley L, Kwan E, et al. Prevalence and penetrance of germline BRCA1 and BRCA2 mutations in a population series of 649 women with ovarian cancer. Am 
J Hum Genet 2001;68:700-10

18. Bar-Sade RB, Kruglikova A, Modan B, Gak E, Hirsh-Yechezkel G, Theodor L, et al. The 185delAG BRCA1 mutation originated before the dispersion of Jews in the diaspora and is not limited to Ashkenazim. Hum Mol Genet 1998;7:801-5.

19. Struewing JP, Hartge P, Wacholder S, Baker SM, Berlin M, McAdams M, et al. The risk of cancer associated with specific mutations of BRCA1 and BRCA2 among Ashkenazi Jews. N Engl J Med 1997;336:1401-8.

20. Csokay B, Tihomirova L, Stengrevics A, Sinicka O, Olah E. Strong founder effects in BRCA1 mutation carrier breast cancer patients from Latvia. Hum Mutation 1999;14:92-96.

21. Gayther SA, Harrington P, Russell P, Kharkevich G, Garkavtseva RF, Ponder BA. Frequently occurring germ-line mutations of the BRCA1 gene in ovarian cancer families from Russia. Am J Hum Genet 1997;60:1239-42.

22. Tikhomirova L, Sinicka O, Smite D, Eglitis J, Hodgson SV, Stengrevics A. High prevalence of two BRCA1 mutations, 4154delA and 5382insC, in Latvia. Fam Cancer 2005;4:77-84

23. Sobczak K, Kozłowski P, Napierała M, Czarny J, Woźniak M,
Kapuścińska M, et al. Novel BRCA1 mutations and more frequent intron-20 alteration found among 236 women from Western Poland. Oncogene 1997;15:1773-9.

24. Elsakov P, Kurtinaitis J, Petraitis S, Ostapenko V, Razumas M, Razumas T, et al. The contribution of founder mutations in BRCA1 to breast and ovarian cancer in Lithuania. Clin Genet 2010;78:373-6.

25. Menkiszak J, Gronwald J, Górski B, Jakubowska A, Huzarski T, Byrski T, et al. Hereditary ovarian cancer in Poland. Int J Cancer 2003; 106:942-5.

26. Roa BB, Boyd AA, Volcik K, Richards CS. Ashkenazi Jewish population frequencies for common mutations in BRCA1 and BRCA2. Nat Genet 1996;14:185-7.

27. Thompson D, Easton D. Breast Cancer Linkage Consortium. Variation in cancer risks, by mutation position, in BRCA2 mutation carriers. Am J Hum Genet 2001;68:410-9.

28. Haber D. Prophylactic oophorectomy to reduce the risk of ovarian and breast cancer in carriers of BRCA mutations. N Engl J Med 2002;346:1660-2. 